\title{
Ceftaroline: A New Cephalosporin with Activity against Methicillin-Resistant Staphylococcus aureus (MRSA)
}

\author{
Christopher Duplessis, MD, MPH ${ }^{1}$ and Nancy F. Crum-Cianflone, MD, MPH ${ }^{1,2}$ \\ 1 Infectious Disease Division, Naval Medical Center San Diego, San Diego, CA United States \\ 2 Infectious Disease Clinical Research Program, Uniformed Services University of the Health \\ Sciences, Bethesda, MD, United States
}

\section{Abstract}

Microbial resistance has reached alarming levels, threatening to outpace the ability to counter with more potent antimicrobial agents. In particular, methicillin-resistant Staphylococcus aureus (MRSA) has become a leading cause of skin and soft-tissue infections and PVL-positive strains have been associated with necrotizing pneumonia. Increasing reports of growing resistance to glycopeptides have been noted, further limiting the efficacy of standard antibiotics, such as vancomycin. Ceftaroline is a novel fifth-generation cephalosporin, which exhibits broad-spectrum activity against Gram-positive bacteria, including MRSA and extensively-resistant strains, such as vancomycin-intermediate $S$. aureus (VISA), heteroresistant VISA (hVISA), and vancomycinresistant $S$. aureus (VRSA). In addition to being an exciting new agent in the anti-MRSA armamentarium, ceftaroline provides efficacy against many respiratory pathogens including Streptococcus pneumoniae, Haemophilus influenzae, and Moraxella catarrhalis. Ceftaroline (600 $\mathrm{mg}$ intravenously every 12 hours) has been shown effective in phase III studies in the treatment of complicated skin and soft tissue infections and community-acquired pneumonia. To date, this unique antibiotic exhibits a low propensity for inducing resistance and has a good safety profile, although further post-marketing data and clinical experience are needed. In summary, ceftaroline provides an additional option for the management of complex multidrug resistant infections, including MRSA.

\section{Keywords}

Ceftaroline; antibiotic; cephalosporin; methicillin-resistant Staphylococcus aureus; MRSA; multidrug resistant organisms

Corresponding Author: Nancy Crum-Cianflone, c/o Clinical Investigation Department (KCA), Naval Medical Center San Diego, 34800 Bob Wilson Drive, Ste. 5, San Diego, CA 92134-1005. Phone: 619/532-8134/40; FAX: 619/532-8137; nancy.crum@med.navy.mil.

Conflict of Interest: None. The authors have no financial interest in this work. Both authors contributed to the content of the manuscript and concurred with the decision to submit it for publication.

The content of this publication is the sole responsibility of the authors and does not necessarily reflect the views or policies of the NIH or the Department of Health and Human Services, the DoD or the Departments of the Army, Navy or Air Force. Mention of trade names, commercial products, or organizations does not imply endorsement by the U.S. Government.

This work is original and has not been published elsewhere.

Disclosures

This manuscript has been read and approved by both authors. This paper is unique and not under consideration by any other publication and has not been published elsewhere. The authors and peer reviewers report no conflicts of interest. The authors confirm that they have permission to reproduce any copyrighted material. 


\section{Introduction}

Microbial pathogens have an extraordinary capacity to develop resistance to antimicrobial agents. Within the last two decades, resistance has escalated, occasionally at seemingly exponential rates, threatening to outpace the ability to counter with more potent antimicrobial agents. Methicillin-resistant Staphylococcus aureus (MRSA), first isolated in the 1960s, became a prominent nosocomial pathogen over the past three decades. The advent of community-associated MRSA (CA-MRSA), which arose de novo outside the healthcare environment, has dramatically heightened the importance of MRSA. Today, MRSA is the leading cause of community-acquired skin and soft tissue infections (SSTI) and a cause of necrotizing pneumonia. ${ }^{1,2}$ The dramatic escalation in MRSA, which is now globally ubiquitous, coupled to intrinsic resistance to many of the existing antimicrobial agents, renders this an enormous public health issue. MRSA has also recently exhibited an inexorable creep in minimum inhibitory concentrations (MIC) to the standard intravenous antibiotic (vancomycin) utilized in its management. In addition, S. aureus strains with vancomycin-intermediate resistance (VISA), heteroresistance (hVISA), and vancomycin resistance (VRSA) have been described. ${ }^{3}$ These resistant strains are associated with increased morbidity and mortality above that of methicillin-sensitive Staphylococcus aureus (MSSA), and often require surgical intervention coupled to a sparse selection of suitable antimicrobial therapy. ${ }^{4}$

Fortunately, alternatives to vancomycin have been developed in the past decade for the treatment of multidrug resistant (MDR) Gram-positive bacterial infections including an oxazolidinone (linezolid), a lipopeptide (daptomycin), a streptogramin (quinupristindalfopristin), and a glycylcycline (tigecycline). ${ }^{5,6}$ Telavancin is a recent addition to the Gram-positive arsenal, and is a lipoglycopeptide which inhibits both bacterial cell wall synthesis and cell-membrane function. ${ }^{7}$

Despite these novel agents, resistance continues to evolve, and strains resistant to linezolid, quinupristin/dalfopristin and daptomycin have been described. ${ }^{5,6,8}$ Moreover, there are disadvantages associated with these contemporary antibiotic classes. For example, linezolid has minimal Gram-negative activity (due to efflux pumps), although it does have some activity against anaerobes and Mycobacteria spp. ${ }^{9}$ Furthermore, linezolid is bacteriostatic and its long-term use (e.g., >2 weeks) has been associated with the development of peripheral neuropathy, lactic acidosis, and thrombocytopenia (as well as the potential for trilineage bone marrow suppression).${ }^{10}$ Daptomycin lacks pulmonary activity, and may cause a pulmonary hypersensitivity reaction and myopathy. ${ }^{11,12}$ Additionally, daptomycin resistance has been noted in the setting of prior vancomycin therapy, especially with suboptimal dosing and sequestered infections including osteomyelitis, endocarditis, and device related infections. ${ }^{13-16}$ Daptomycin resistance had been linked to its inactivity in the setting of thickened cell walls in VISA and hVISA isolates, with reduced access to binding sites on the cell membrane, and to point mutations leading to amino acid substitutions in the $\mathrm{MprF}$ and $\mathrm{YycG}$ proteins ${ }^{16}$. Quinupristin-dalfopristin is limited by its administration via central venous access, its only modest activity against MRSA pneumonia, and a host of adverse side-effects including myalgias. ${ }^{6}$ Tigecycline is active against a range of both Grampositive and -negative organisms (notably excluding $P$. aeruginosa), and approved for the treatment of SSTI and complicated intra-abdominal infections ${ }^{17}$. However, it exhibits low serum concentrations, accumulates in bone (contraindicated in children and pregnancy), and is often associated with significant nausea. ${ }^{18}$ Furthermore in a recent multicenter trial, tigecycline (+/- ceftazidime $+/-$ aminoglycoside) versus imipenem (+/-vancomycin $+/-$ aminoglycoside) had significantly lower cure rates for ventilator-associated pneumonia $(\mathrm{VAP})^{19}$, and the FDA has issued a warning that tigecycline may be associated with an increased mortality risk compared to other drugs for treatment of a variety of serious 
infections including VAP. Telavancin may also cause nausea and vomiting, and it has been associated with infusion-related reactions (i.e., red-person syndrome). ${ }^{7}$ Finally, many of these unique agents (i.e., linezolid, daptomycin, and telavancin) are only active against Gram-positive bacteria.

Ceftaroline fosamil (brand name Teflaro, previously referred to as PPI-0903M, T-91825, TAK-599) is a novel fifth-generation parental oxyimino cephalosporin with bactericidal activity against MRSA (Figure 1). ${ }^{20,21}$ In contrast to most of the aforementioned MRSA antimicrobials, ceftaroline fosamil (hereafter, ceftaroline) exhibits broad-spectrum activity against many of the important community-acquired Gram-positive and Gram-negative pathogens, ${ }^{20-22}$ similar to the sole other fifth-generation cephalosporin (ceftobiprole) in development.

Importantly, it has activity against MDR Gram-positive bacteria, including MRSA, VISA, hVISA, and VRSA. ${ }^{23,24}$ It also has efficacy against respiratory bacterial pathogens such as Streptococcus pneumoniae (including multidrug-resistant strains), Haemophilus influenzae, and Moraxella catarrhalis. Mirroring other broad-spectrum cephalosporins, ceftaroline does not possess activity against extensively-resistant Gram-negative bacteria and exhibits limited activity against most non-fermentative Gram-negative bacilli (e.g., Pseudomonas aeruginosa, Acinetobacter spp.) and many anaerobic species. ${ }^{20-23}$

A new drug application for ceftaroline (Forest Laboratories Inc., New York, NY) was submitted in December 2009, with the specific indications for the treatment of complicated SSTI and community-acquired pneumonia (CAP). This novel drug gained FDA approval in September 2010 and is expected to be available for use in early 2011.

\section{Mechanism of Action}

Like other $\beta$-lactams, ceftaroline's mechanism of action is mediated by binding to the penicillin-binding protein ( $\mathrm{PBP}$ ), the enzyme mediating the cross-linking transpeptidation of the peptidoglycan which are the terminal steps in completing formation of the bacterial cell wall. MRSA strains have a mutated PBP2a (coded by the mecA gene residing on the staphylococcal chromosomal cassette), which prohibits $\beta$-lactam antibiotics from accessing its active site that mediates the transpeptidation reaction. The interaction of PBP2a at an allosteric site within peptidoglycan triggers conformational changes potentiating access to the active state. When not actively involved in transpeptidation, the active site is closed, effectively "shielded" from potential $\beta$-lactam antibiotics. ${ }^{25}$ Ceftaroline possesses an ethoxyimino side-chain mimicking a portion of a cell wall structure, which acts as a "Trojan horse", allosterically opening and facilitating access to the active site of the PBP2a. ${ }^{25,26}$

More specifically, $\beta$-lactam antibiotics form a non-covalent complex with the transpeptidase enzymatic domain of the PBP. This is characterized by an equilibrium dissociation constant, $K_{D}$, which is converted to the covalent acyl-enzyme form with a rateconstant, $k_{2}$. The acylenzyme complex prevents transpeptidation, and as free enzyme regeneration via hydrolytic deacylation characterized by the rate constant $\left(k_{3}\right)$ is slow (eclipsing duration of cell viability) the bacteria undergoes lysis. Now the dissociation constant for the non-covalent interaction of the transpeptidase enzymatic region of PBP2a with the $\beta$-lactam is very high due to structural inaccessibility of the $\beta$-lactam due to the presence of a peptide loop shielding the active site of PBP2a. Binding of muropeptide of peptidoglycan to an allosteric site of the PBP2a potentiates a conformation change displacing the peptide loop enabling access of substrate for wall synthesis. Ceftaroline possesses a side chain mimetic of the muropeptide which can interact with the allosteric site of PBP2a duplicating the conformational change necessary to displace the peptide loop shielding access, allowing 
formation of the initial non-covalent interaction of the transpeptidase enzymatic region of PBP2a with the $\beta$-lactam. ${ }^{27}$ (Figure 2).

Hence, ceftaroline's anti-MRSA efficacy stems from high affinity for the MRSA-associated PBP2a (perhaps $\geq 256$-fold over other $\beta$-lactams). For example, the $\mathrm{MIC}_{50}$ for the PBP2a for ceftaroline is $0.90 \mu \mathrm{g} / \mathrm{ml}$ compared with $408 \mu \mathrm{g} / \mathrm{ml}$ for oxacillin, $677 \mu \mathrm{g} / \mathrm{ml}$ for ceftriaxone, and $57 \mu \mathrm{g} / \mathrm{ml}$ for imipenem. The inhibition of PBP by ceftaroline results in cell wall irregularities and eventual bacterial cell death. ${ }^{28}$ Ceftaroline also demonstrates superior affinity for all the prominent PBPs utilized within both sensitive (PBP 1-3) and resistant strains of $S$. aureus. Furthermore, it has activity to the mutable PBPs of $S$. pneumoniae including multiple drug-resistant S. pneumoniae (MDRSP) (PBP1a, PBP2a, PBP2b, PBP2x, PBP3) and the PBP3 of Gram-negative bacteria. ${ }^{28,}{ }^{29}$ Finally, ceftaroline remains effective in the setting of the cell wall changes which mediate resistance within VISA, hVISA, VRSA, and daptomycin-resistant isolates..$^{22,24,30}$

\section{Pharmacokinetics}

Ceftaroline is the bioactive metabolite of ceftaroline fosamil, an $\mathrm{N}$-phosphonoamino watersoluble cephalosporin prodrug, which is rapidly converted in vivo upon the hydrolysis of the phosphonate group by plasma phosphatises. ${ }^{23}$ Ceftaroline's chemical stability and water solubility is attributed in part from improved crystallization and hygroscopicity imparted by innovated chemical modifications, necessitating administration as a prodrug via intravenous or intramuscular routes.

Following single $500 \mathrm{mg}$ and $750 \mathrm{mg}$ intravenous doses, ceftaroline reaches peak serum concentration (Cmax) of 16.5 and $23 \mu \mathrm{g} / \mathrm{ml}$, respectively, and steady state AUC values of 44.7 and $56.9 \mu \mathrm{g} / \mathrm{hour} / \mathrm{ml}$, respectively. Escalating single doses of ceftaroline fosamil (50 to $1000 \mathrm{mg}$ ) administered intravenously as one-hour infusions to healthy male individuals ( $\mathrm{n}=$ 48) yielded ceftaroline concentrations ranging from 1.5 to $30.2 \mu \mathrm{g} / \mathrm{ml}$; mean half-lives of ceftaroline fosamil, ceftaroline, and the major metabolite (ceftaroline-M-1) were 0.4, 2.4, and 4.5 hours, respectively. ${ }^{31}$

Multiple escalating doses of ceftaroline fosamil were administered intravenously in healthy male subjects as 300 and $600 \mathrm{mg}$, respectively, every 12 hours for 14 days, and $800 \mathrm{mg}$ every 24 hours for 7 days. Ceftaroline again formed rapidly after dosing, exhibiting a halflife of 2.6 (range 2.3-2.9) hours. The values of Cmax, AUC and clearance for the three respective groups were: Cmax: 8.4, 21, and $31 \mu \mathrm{g} / \mathrm{ml}$; AUC: 24,56 , and $73 \mu \mathrm{g} / \mathrm{hour} / \mathrm{ml}$; clearance: 183,159 , and $161 \mathrm{ml} / \mathrm{min}$, respectively. For multiple intravenous doses of $600 \mathrm{mg}$ given over one hour every 12 hours for 14 days, the maximum plasma concentration was $19.0 \mu \mathrm{g} / \mathrm{ml}$ and $21.0 \mu \mathrm{g} / \mathrm{ml}$ for first and last doses, respectively, without evidencing drug accumulation with multiple dosing. ${ }^{31,32}$

The intramuscular route of delivery is attractive, given its potential convenience of administration. In animal models, intramuscular administration exhibited similar pharmacokinetics to that of intravascular administration with almost $100 \%$ bioavailability. 26,33 The AUCs for the intramuscular route was comparable to that achieved with intravenous dosing in both rabbits (mean AUC 7.3\% greater) and monkeys (12.7\% greater), indicating excellent bioavailability via this route. ${ }^{33}$ In addition, the half-lives of the two routes were comparable. The time to achieve Cmax was slightly longer, with intramuscular administration and initial peak levels slightly lower, perhaps due to the slower release of the pro-drug from the intramuscular site. Data showing near equivalence regarding intramuscular and intravenous routes have also been noted in human studies. ${ }^{34}$ 
Ceftaroline's volume of distribution is an estimated $0.37 \mathrm{~L} / \mathrm{kg}$, corresponding to the extracellular fluid volume of about 16-17 liters with plasma protein binding of $<20 \%$. $23,35,36$ Establishing pulmonary tissue penetration was imperative in seeking approval for an indication to treat CAP. The mean pulmonary penetration in a rabbit model was $42 \%(+/-$ $11.2 \%$ ) relative to plasma levels over two hours; intravenous dosing was administered at 20 $\mathrm{mg} / \mathrm{kg}$ for 30 minutes, with plasma and lung tissue concentrations of $41.0 \mathrm{mg} / \mathrm{L}$ and 18.7 $\mathrm{mg} / \mathrm{kg}$, respectively. Further, the pulmonary concentrations exceeded the MICs of most respiratory pathogens. ${ }^{37}$ Assessment of pulmonary penetration in human studies is pending. Furthermore, pharmacokinetic studies await evaluation of cerebrospinal fluid penetration. If ceftaroline provides adequate CSF penetration, coupled to its impressive anti-MDRSP activity, ${ }^{38}$ ceftaroline would offer a promising option against bacterial meningitis.

Elimination (drug clearance) occurs primarily through renal excretion, exhibiting classical two-compartmental linear pharmacokinetics with upwards of $75 \%$ of drug recovered in urine $(52+/-33 \%)$. After conversion from the prodrug ceftaroline fosamil to ceftaroline, a small fraction of the latter is converted to an inactive metabolite, ceftaroline-M-1. Approximately $50 \%$ of ceftaroline (clearance ranging from 90.0 to $129.2 \mathrm{ml} / \mathrm{min}$ ) and $7 \%$ of ceftarolineM-1 are excreted in the urine. ${ }^{31,32,35}$

In a small study ( $\mathrm{n}=18,6$ per group), individuals with normal renal function (creatinine clearance $(\mathrm{CrCl})>80 \mathrm{ml} / \mathrm{min})$, mild renal impairment $(\mathrm{CrCl}$ of $51-80 \mathrm{ml} / \mathrm{min})$, or moderate renal impairment $(\mathrm{CrCl}$ of $31-50 \mathrm{ml} / \mathrm{min})$ received ceftaroline fosamil $(600 \mathrm{mg})$ as an onehour intravenous infusion, with subsequent plasma and urine collections for up to 48 hours. Ceftaroline exhibited an increasing plasma half-life with increased renal impairment from $2.8,3.6$, to 4.5 hours, respectively. The Cmax of ceftaroline was unaffected by renal function, ranging from 27 to $31 \mu \mathrm{g} / \mathrm{ml}$, while AUC values increased with worsening renal function: 68 to $120 \mu \mathrm{g} / \mathrm{hour} / \mathrm{ml}$, with a commensurate reduction in the clearance from 126 to $74 \mathrm{ml} / \mathrm{min}$. The renal clearance of ceftaroline and ceftaroline-M-1 was decreased significantly by $65 \%$ and $84 \%$, respectively. ${ }^{35}$

Based on Monte Carlo simulations, dosage adjustment is recommended for patients with moderate renal impairment (creatinine clearance $31-50 \mathrm{ml} / \mathrm{min}$ ) at $400 \mathrm{mg}$ intravenously (infused over one hour) every 12 hours. No dosage adjustment is necessary for mild renal impairment $(\mathrm{CrCl}>50 \mathrm{ml} / \mathrm{min}) .{ }^{35,39}$ There are no recommendations for dosing in severe renal dysfunction $(\mathrm{CrCl}<30 \mathrm{ml} / \mathrm{min})$ or hemodialysis available at this time, but some pharmacokinetic data suggest that a dose reduction of at least $50 \%$, or doubling of the dosing interval will be warranted among these patients. ${ }^{40,41}$

Ceftaroline lacks a p450-dependent mechanism of metabolism and is unlikely to interfere with drugs metabolized through cytochromes in the liver. ${ }^{42}$ Minimal ceftaroline was recovered in the bile or intestines after administration, further confirming that most of the drug is excreted renally and suggesting minimal hepatic influence on pharmacokinetics. ${ }^{43}$ In addition, hepatic impairment will likely have minimal influence on ceftaroline dosing.

\section{Pharmacodynamics}

The $\% \mathrm{~T}>\mathrm{MIC}$ is the most important pharmokinetic/pharmacodynamic parameter, predicting ceftaroline's clinical efficacy consistent with the $\beta$-lactam antibiotic class. Target attainment studies performed with cephalosporins reported that bacteriostatic and bactericidal effects are achieved for staphylococci when free drug concentrations exceed the MIC for $30 \%$ or $50 \%$ of the dosing interval, respectively. As true for the cephalosporin class, superior pharmacokinetic/pharmacodynamic efficacy correlates with the duration (and not the peak concentrations) eclipsing the MIC. ${ }^{23,26,44}$ The $\% \mathrm{~T}>$ MIC necessary to produce $1 \log$ killing were $43 \pm 9 \%$ (S. pneumoniae), $33 \pm 9 \%$ (S. aureus), and $41 \pm 11 \%$ (Gram- 
negative bacilli). The data for $2 \log$ killing were $50 \pm 10 \%$ (S. pneumoniae), $45 \pm 13 \%$ ( $S$. aureus), and $54 \pm 3 \%$ (Gram-negative Enterobacteriaceae bacilli), respectively, in a murine model.

A population pharmacokinetic analysis of data from phase I and II trials for ceftaroline found that the probability of target attainment for $\% \mathrm{~T}>\mathrm{MIC}$ of $50 \%$ for a $1-\mu \mathrm{g} / \mathrm{ml}$ target was $96 \%$ and $50 \%$ for a $2-\mu \mathrm{g} / \mathrm{ml}$ target, assuming subjects with normal renal function and administered $600 \mathrm{mg}$ ceftaroline over a one-hour infusion every 12 hours. The ceftaroline MIC distribution for susceptible bacteria is narrow, with only $4.5 \%$ of the strains displaying a MIC of $\leq 0.25 \mu \mathrm{g} / \mathrm{ml}$ and $1.5 \%$ with a MIC of $\geq 2 \mu \mathrm{g} / \mathrm{ml}$. The $\mathrm{MIC}_{50}$ and $\mathrm{MIC}_{90}$ rarely deviate significantly, as minimum bactericidal concentration (MBC) values are consistently equal to, or within a single dilution higher than, their respective MICs for $86 \%$ of tested organisms, while $90 \%$ of strains had an ideal MBC/MIC ratio of $\leq 4 .{ }^{38}$ Kill-curve kinetic studies corroborated MBC determinations for ceftaroline, as bactericidal ( $\geq 3 \log _{10} \mathrm{CFU} / \mathrm{ml}$ reductions) action could be demonstrated in the majority of strains at up to eight times the reference MIC tested. ${ }^{45}$

Ceftaroline breakpoints have been proposed, but not confirmed, since the final MIC values and disc diffusion breakpoints await analyses of the results from Phase III clinical trials. ${ }^{22,26}$ Susceptible Gram-positive quality control strains all had zone diameters exceeding $>20 \mathrm{~mm}$ for the 10-100 $\mu \mathrm{g}$ disc concentrations and a corresponding MIC $\leq 0.5 \mu \mathrm{g} / \mathrm{ml}$. The maximum zone diameter differences of approximately $10 \mathrm{~mm}$ were achieved between susceptible and possibly resistant strains utilizing the 10 or $30 \mu \mathrm{g}$ disc. Therefore, the 10 or $30 \mu \mathrm{g}$ disc content may be a reasonable choice for potential correlation of MIC breakpoints of $\leq 1-4 \mu \mathrm{g}$ / $\mathrm{ml}^{22,45,46}$

As PBP affinity correlates with the MIC, predictably, ceftaroline enjoys superior efficacy (i.e., reduced MICs) to that of contemporary $\beta$-lactams. ${ }^{28}$ This is best illustrated with high binding affinity of ceftaroline to PBP2a associated with superior MICs against MRSA $(0.05-2 \mu \mathrm{g} / \mathrm{ml}) .{ }^{24}$ An apparent relatively lengthy post antibiotic effect (PAE) has been noted in treatment of Gram-positive organisms, especially $S$. aureus, which could prevent bacterial re-growth when ceftaroline levels in serum fall below the MIC. ${ }^{47}$ Predictably and consistent with the cephalosporin class, ceftaroline fails to achieve a significant PAE against most other types of bacteria. ${ }^{26}$ Bacterial re-growth has been uncorrelated to resistance, drug instability, or tolerance, thus far. Preliminary data suggest that the in vivo activity of ceftaroline parallels the in vitro MICs. ${ }^{48}$

\section{Microbiology}

Ceftaroline, in contradistinction to other drugs within the cephalosporin class, has good efficacy against MRSA, VISA, hVISA, and VRSA; linezolid- and daptomycin-resistant $S$. aureus; and MDRSP, while retaining efficacy against numerous Gram-negative pathogens including respiratory and non-extended-spectrum $\beta$-lactamases (ESBL) producing Enterobacteriaceae (Table 1). ${ }^{20,21,23,38}$

\section{Gram-Positive Organisms}

Ceftaroline has 16-fold greater activity than ceftriaxone against MSSA isolates. For example, ceftaroline's $\mathrm{MIC}_{90}$ is consistently reported to be $0.25 \mu \mathrm{g} / \mathrm{ml}(\leq 0.03-1 \mu \mathrm{g} / \mathrm{ml})$ for MSSA, compared with $4 \mu \mathrm{g} / \mathrm{ml}$ for ceftriaxone, $1 \mu \mathrm{g} / \mathrm{ml}$ for vancomycin, and $\leq 0.12 \mu \mathrm{g} / \mathrm{ml}$ for imipenem. Ceftaroline demonstrated up to four-fold greater activity than vancomycin against MRSA isolates, independent of the isolate's source (blood, skin, or respiratory tract), demonstrating MIC and MBC values ranging between 0.125 to $2 \mu \mathrm{g} / \mathrm{ml}$ and 0.5 to $2 \mu \mathrm{g} / \mathrm{ml}$ for ceftaroline and vancomycin, respectively. ${ }^{20,} 21,49$ As expected, ceftaroline was $\geq 8$-fold 
more potent than cefepime and $\geq 16$-fold more active than ceftriaxone against MRSA strains. ${ }^{42}$ Ceftaroline MIC $_{90}$ values against MRSA were $0.5-2 \mu \mathrm{g} / \mathrm{ml}$, similar to that of linezolid and vancomycin $\left(\mathrm{MIC}_{90}\right.$ of $\left.1-2 \mu \mathrm{g} / \mathrm{ml}\right) .{ }^{49}$ Moreover, the MBC against MRSA strains were 1,2 , and $>64 \mu \mathrm{g} / \mathrm{ml}$, respectively, for ceftaroline, vancomycin, and linezolid.

Ceftaroline's superiority over vancomycin was evident in hVISA, VISA, and VRSA as well as MRSA strains concomitantly resistant to linezolid and daptomycin. ${ }^{50-52}$ The MICs and MBCs for hVISA strains ( $\mathrm{n}=100$ isolates) were $2(0.25-4 \mu \mathrm{g} / \mathrm{ml})$ and $2 \mu \mathrm{g} / \mathrm{ml}$, respectively, for ceftaroline. The corresponding MICs and MBCs were 4 and $8 \mu \mathrm{g} / \mathrm{ml}$, respectively, for vancomycin and 1 and $16 \mu \mathrm{g} / \mathrm{ml}$, respectively, for linezolid. ${ }^{44}$ Ceftaroline yielded MICs of $1-4 \mu \mathrm{g} / \mathrm{ml}$ against both linezolid-sensitive and -resistant $S$. aureus isolates. Additionally, ceftaroline exhibited bactericidal effects, as opposed to the slowly bactericidal activity exhibited by vancomycin and the bacteriostatic activity of linezolid, and has synergy in combination with tobramycin. ${ }^{50}$ Finally, ceftaroline's MIC values against quinupristindalfopristin-resistant strains were similar in activity to that described for MRSA (MIC ${ }_{50}$ and $\left.\mathrm{MIC}_{90}, 1 \mu \mathrm{g} / \mathrm{ml}\right)^{21}$

Ceftaroline is also active against coagulase-negative Staphylococcus epidermidis (CoNS). Ceftaroline exhibited $\mathrm{MIC}_{90}$ of $0.12(0.06-0.12)$ and $0.5(0.25-2.0) \mu \mathrm{g} / \mathrm{ml}$ for oxacillinsusceptible and oxacillin-resistant isolates of CoNS, respectively. ${ }^{20,} 21,49$ Ceftaroline demonstrated MICs of $\leq 0.016$ to $2 \mu \mathrm{g} / \mathrm{ml}$ against CoNS strains having reduced susceptibility to vancomycin (MIC of $4 \mu \mathrm{g} / \mathrm{ml}$ ). ${ }^{21}$ Ceftaroline was also active against 15 quinupristindalfopristin- and linezolid-nonsusceptible isolates ( $\mathrm{MIC}_{90}, 1.0 \mu \mathrm{g} / \mathrm{ml}$ and $0.5 \mu \mathrm{g} / \mathrm{ml}$ ), respectively. ${ }^{21}$

Consistent with other cephalosporins, the $\mathrm{MIC}_{90}$ value is lower against penicillinsusceptible strains of $S$. pneumoniae $\left(\mathrm{MIC}_{90}=0.015 \mu \mathrm{g} / \mathrm{ml}\right.$ ) than against penicillinintermediate $(0.06 \mu \mathrm{g} / \mathrm{ml})$ or penicillin-resistant strains $(0.12-0.25 \mu \mathrm{g} / \mathrm{ml}) .{ }^{38,53,54}$ Moreover, MICs (both $\mathrm{MIC}_{50}$ and $\mathrm{MIC}_{90}$ ) varied between $<0.008$ and $0.5 \mu \mathrm{g} / \mathrm{ml}$ against 891 clinical human pneumococcal isolates collected from 22 centers in the United States in $2008 .^{53,54}$ Ceftaroline remained highly active, regardless of penicillin-susceptibility status ( $\mathrm{MIC}_{90} \leq 0.5$ $\mu \mathrm{g} / \mathrm{ml})$, levofloxacin- susceptibility, and MDR strains, remaining 2-16 fold more active than other $\beta$-lactam comparators, including cefotaxime, ceftriaxone (MIC $=1$ to $2 \mu \mathrm{g} / \mathrm{ml}$ ), amoxicillin $(8 \mu \mathrm{g} / \mathrm{ml})$, meropenem, cefepime, and the new cephalosporin ceftobiprole $(1 \mu \mathrm{g} /$ $\mathrm{ml}) .{ }^{20,21,40,} 42,54,55$ The MBC/MIC ratios for ceftaroline were also lower than all comparators to penicillin-susceptible and penicillin non-susceptible isolates. ${ }^{55}$ Ceftaroline ( $\mathrm{MIC}_{90} 0.03 \mu \mathrm{g} / \mathrm{ml}$ ) was superior in isolates containing known mutations within the PBPs (i.e., $1 \mathrm{~A}, 2 \mathrm{~B}$, and $2 \mathrm{X}$ ) exhibiting $\mathrm{MIC}_{90}$ values against MDRSP of $0.25 \mu \mathrm{g} / \mathrm{ml} .{ }^{42,45}$ Ceftaroline maintained MICs of $1.0 \mu \mathrm{g} / \mathrm{ml}$ against penicillin- and ceftazidime-resistant $S$. pneumoniae and $\mathrm{MIC}_{90}$ of $0.5 \mu \mathrm{g} / \mathrm{ml}(0.125-2.0 \mu \mathrm{g} / \mathrm{ml})$ against highly cephalosporinresistant clinical isolates of $S$. pneumoniae (cefotaxime and ceftriaxone MIC $_{90} \geq 4-16 \mu \mathrm{g}$ / $\mathrm{ml}) .{ }^{49}$ Against amoxicillin- and cefotaxime-resistant strains, the ceftaroline $\mathrm{MIC}_{90}(0.25 \mu \mathrm{g} /$ $\mathrm{ml}$ ) was four and 16 times lower, respectively, than that of ceftriaxone ( 1 and $4 \mu \mathrm{g} / \mathrm{ml}$, respectively). Ceftaroline's $\mathrm{MIC}_{90}$ against erythromycin- and levofloxacin-resistant strains were $0.25 \mu \mathrm{g} / \mathrm{ml}$ and $0.12 \mu \mathrm{g} / \mathrm{ml}$, respectively. ${ }^{53-56}$

Ceftaroline exhibits excellent potency against $\beta$-hemolytic streptococci, including Streptococcus pyogenes and Streptococcus agalactiae, with the vast majority of strains inhibited at a $\mathrm{MIC}_{90} \leq 0.008-0.016 \mu \mathrm{g} / \mathrm{ml}$, irrespective of macrolide- and levofloxacinsusceptibility status. ${ }^{42}$ Ceftaroline retained $\mathrm{MIC}_{50}$ and $\mathrm{MIC}_{90}$ of 0.03 and $0.5 \mu \mathrm{g} / \mathrm{ml}$ for penicillin-susceptible and penicillin-resistant viridans group streptococci strains, respectively, irrespective of levofloxacin-susceptibility status. ${ }^{20,56}$ Quinupristin- 
dalfopristin-nonsusceptible Streptococcus bovis and S. mitis strains were also sensitive to ceftaroline, exhibiting MICs varying widely from $\leq 0.016-8 \mu \mathrm{g} / \mathrm{ml} .^{21}$

Ceftaroline exhibits an $\mathrm{MIC}_{90}$ of $4 \mu \mathrm{g} / \mathrm{ml}(0.25-8 \mu \mathrm{g} / \mathrm{ml})$ for Enterococcus faecalis, irrespective of vancomycin-, linezolid-, quinupristin-dalfopristin-, or ampicillinsusceptibility status. Ceftaroline MICs varied from $2-4 \mu \mathrm{g} / \mathrm{ml}$ against vancomycin- sensitive and -resistant E. faecalis strains (including $\operatorname{Van}^{\mathrm{r}}$ ). ${ }^{20,21,48}$ However, ceftaroline yielded minimal activity against vancomycin-susceptible or - resistant Enterococcus faecium isolates with $\mathrm{MIC}_{90}$ of $16-64 \mu \mathrm{g} / \mathrm{ml}^{21,42,48,49}$

\section{Gram-Negative Organisms}

MICs against Enterobacteriaceae isolates without $\beta$-lactamases range from 0.06-4 $\mu \mathrm{g} / \mathrm{ml}$ (typically with a $\mathrm{MIC}_{90}$ of $1 \mu \mathrm{g} / \mathrm{ml}$, Table 1 ), exhibiting similar to modestly inferior activity compared to cefepime, ceftazidime, cefotaxime, and ceftriaxone. ${ }^{20,21,42}$ Example MICs for non-ESBL producing Enterobacteriaceae isolates include Citrobacter freundii $\left(\mathrm{MIC}_{50} 0.15\right.$ $\left.\mu \mathrm{g} / \mathrm{ml} ; \mathrm{MIC}_{90}, 2 \mu \mathrm{g} / \mathrm{ml}\right)$, E. coli $\left(\mathrm{MIC}_{50} 0.06 \mu \mathrm{g} / \mathrm{ml} ; \mathrm{MIC}_{90}, 0.12 \mu \mathrm{g} / \mathrm{ml}\right)$, Klebsiella pneumoniae $\left(\mathrm{MIC}_{50} 0.06 \mu \mathrm{g} / \mathrm{ml} ; \mathrm{MIC}_{90}, 0.5 \mu \mathrm{g} / \mathrm{ml}\right.$ ), Morganella morganii $\left(\mathrm{MIC}_{50} 0.06 \mu \mathrm{g}\right.$ / $\mathrm{ml} ; \mathrm{MIC}_{90}, 0.12 \mu \mathrm{g} / \mathrm{ml}$ ), Proteus mirabilis ( $\mathrm{MIC}_{50} 0.06-0.5 \mu \mathrm{g} / \mathrm{ml} ; \mathrm{MIC}_{90}, 0.12 \mu \mathrm{g} / \mathrm{ml}$ ), and Serratia marcescens ( $\mathrm{MIC}_{50} 0.12-1 \mu \mathrm{g} / \mathrm{ml} ; \mathrm{MIC}_{90}, 2.0 \mu \mathrm{g} / \mathrm{ml}$ ). Ceftaroline also exhibits potent activity in vitro against the respiratory pathogens, $H$. influenzae and $M$. catarrhalis regardless of $\beta$-lactamase production (including ampicillin-resistant strains). For example, the $\mathrm{MIC}_{90}$ is $\leq 0.016-0.03 \mu \mathrm{g} / \mathrm{ml}$ for $H$. influenzae. ${ }^{20,21}$

Mirroring its predecessor oxyimino cephalosporins, ceftaroline lacks activity against ceftazidime non-susceptible Enterobacteriaceae. In addition, ceftaroline demonstrated generally poor activity (i.e., $\mathrm{MIC}_{90}$ of $\geq 32 \mu \mathrm{g} / \mathrm{ml}$ ), similar to ceftriaxone and inferior to cefepime, ceftazidime, and imipenem against a diverse group of nonfermentative Gramnegative bacilli.

Saliently, ceftaroline does not exhibit reliable activity against Pseudomonas spp., Acinetobacter spp., or Stenotrophomonas spp. The $\mathrm{MIC}_{50}$ against Pseudomonas aeruginosa ranges from 2-16 $\mu \mathrm{g} / \mathrm{ml}$, while the $\mathrm{MIC}_{90}$ exceeds $32 \mu \mathrm{g} / \mathrm{ml}$; hence, ceftaroline is not considered active against this organism. The MICs for Acinetobacter spp. isolates ranges from $4->128 \mu \mathrm{g} / \mathrm{ml}$, and for Stenotrophomonas maltophilia, the $\mathrm{MIC}_{90}$ is typically $\geq 32 \mu \mathrm{g} /$ $\mathrm{ml}^{20,21}$

Against classical $\beta$-lactamases, such as TEM-1, TEM-2, or SHV-1, MICs have a significant variability ranging from $2-16 \mu \mathrm{g} / \mathrm{ml}$. Additionally, ceftaroline exhibits (rather uniquely for an oxyimino cephalosporin) mild labiality to classic TEM and SHV $\beta$-lactamases, exhibiting four-fold elevations in its MICs, with high inoculums or with isolates upregulating their expression (demonstrated in many isolates of E. coli, P. mirabilis, and Klebsiella spp.). For example, ceftaroline MICs varied from $0.015-0.03 \mu \mathrm{g} / \mathrm{ml}$ to $0.5-2.0 \mu \mathrm{g} / \mathrm{ml}$ in E. coli isolates with and without classical TEM/SHV $\beta$-lactamases. ${ }^{49}$

Consistent with the cephalosporin class, ceftaroline exhibits little activity and is inactivated by ESBL-producing Enterobacteriaceae isolates ( $\mathrm{MIC}_{90} \geq 32 \mu \mathrm{g} / \mathrm{ml}$ ), particularly compromised against CTX-M ESBL (the predominant ESBL in much of Europe, Asia, and South America). Ceftaroline also exhibits high MICs (>128 $\mu \mathrm{g} / \mathrm{ml})$ against bacteria containing AmpC enzymes (derepressed or constitutively expressed) and carbapenemases (OXA-48, KPC, K1, and metallo- $\beta$-lactamases). ${ }^{20,21,49}$

Studies are underway to examine the potential protection with a $\beta$-lactamase inhibitors (clavulanic acid and tazobactam), which could markedly reduce the MICs of ceftaroline 
potentially restoring activity against ESBL-producing isolates, including classical- and extended-spectrumclass A (TEM, SHV) and D (OXA) $\beta$-lactamases, as well as the K1 carbapenemases. Forest Laboratories is developing a combination product consisting of ceftaroline and NXL104, a novel $\beta$-lactamase inhibitor, to enhance activity against ESBLs and AmpCs; the effectiveness of this combination is under evaluation. Preliminary chequerboard analysis suggests potentiation of ceftaroline activity against Enterobacteriaceae producing AmpCs, KPCs (K1 enzyme), and non-metalloenzymatic $\beta$ lactamases (including OXA-48 carbapenemases), including isolates with impermeability. ${ }^{57}$ Furthermore, NXL104 has been shown to potentiate ceftazidime activity against nonfermenting Pseudomonas aeruginosa (including isolates producing AmpC with MICs decreased to $<8 \mu \mathrm{g} / \mathrm{ml}$ ) and ESBLs (except those exhibiting up-regulated efflux). ${ }^{58}$

\section{Anaerobic Organisms}

Ceftaroline possesses activity against Gram-positive anaerobes, including Peptostreptococcus spp., Propionibacterium spp., and non-difficile Clostridium spp. similar to that of amoxicillin-clavulanate, and $4-8$ fold superior to ceftriaxone (Table 1). It also has good activity against Pasteurella multocida with an $\mathrm{MIC}_{90}$ of $0.06 \mu \mathrm{g} / \mathrm{ml} .{ }^{20}$ It has minimal activity against Bacteroides spp. and Prevotella spp. ( $\mathrm{MIC}_{90} \geq 32 \mu \mathrm{g} / \mathrm{ml}$ ). It possesses similar activity to that of ceftriaxone against Gram-negative non- $\beta$-lactamase producing anaerobes, and possesses insignificant activity against Clostridium difficile $\left(\mathrm{MIC}_{50}, 2 \mu \mathrm{g} / \mathrm{ml}\right.$; $\left.\mathrm{MIC}_{90}, 4 \mu \mathrm{g} / \mathrm{ml}\right)^{21,59}$

\section{Animal Studies}

Animal studies on the efficacy of ceftaroline are summarized in Table 2. In a murine pyomyositis model, ceftaroline and linezolid were both superior to vancomycin $(p \leq 0.01){ }^{60}$ Ceftaroline demonstrated superior efficacy to vancomycin and linezolid in a rabbit model of joint infection due to MRSA and VISA isolates by reducing the CFU/gram tissue of MRSA in synovium by $-1.98 \log _{10}$. Finally, ceftaroline and linezolid (but not vancomycin) significantly reduced bacterial counts by means of -2.95 and $-2.69 \log _{10} \mathrm{CFU} / \mathrm{gram}$ in bone marrow tissue, and -2.83 and $-2.25 \log _{10} \mathrm{CFU} /$ gram in bone, respectively. Overall, ceftaroline was the only intervention demonstrating homogeneous in vivo activity against MRSA and VISA isolates in all three tissues (i.e., synovium, bone, and bone marrow). ${ }^{60,61}$

In a murine MRSA pneumonia model, ceftaroline had similar efficacy in decreasing MRSA bacteria counts than that of vancomycin and linezolid when the drugs were begun within two hours of infection. However, ceftaroline started one day after infection demonstrated more than $99.9 \%$ reduction in bacterial counts by day 3 in a murine MRSA neutropenic pneumonia model, whereby linezolid and vancomycin had no effect. ${ }^{60}$

Regarding the treatment of endocarditis, ceftaroline demonstrated bactericidal activity in a rabbit model by showing a $6 \log _{10}$ decrease in MRSA and VISA isolates after four days of treatment. ${ }^{52}$ Ceftaroline was superior to linezolid and comparable to vancomycin in an aortic endocarditis rabbit model with MRSA $\left(10^{8} \mathrm{CFU}\right)$, decreasing counts to $2.5+/-0.3$ $\log _{10} \mathrm{CFU} /$ gram vegetation compared to $7.1+/-0.6 \log _{10} \mathrm{CFU} / \mathrm{gram}$ in linezolid, $2.7+/-$ $0.8 \log _{10} \mathrm{CFU} / \mathrm{gram}$ in vancomycin, and $8.9+/-0.5 \log _{10} \mathrm{CFU} / \mathrm{gram}$ vegetation in controls. ${ }^{52}$ Ceftaroline was the only bactericidal agent against VISA isolates (wherein both vancomycin and linezolid proved to be bacteriostatic). Regarding sterilization rates (no bacterial growth after 48 hours of incubation), ceftaroline achieved sterilization in $90 \%$ (9/10) of MRSA and 60\% (6/10) of VISA compared to vancomycin, which achieved $67 \%$ (4/6) and $0 \%(0 / 5)$, respectively, and linezolid achieving $0 \%(0 / 7$ and $0 / 8)$ against both isolates. ${ }^{52}$ 
In the same rabbit endocarditis model, ceftaroline was superior in decreasing bacterial vegetations (5.68 $\left.\log _{10} \mathrm{CFU} / \mathrm{gram}\right)$ induced by vancomycin-susceptible $E$. faecalis strains compared to linezolid (6.88 $\log _{10}$ CFU/gram, $p<0.05$ ), vancomycin $\left(6.70 \log _{10} \mathrm{CFU} / \mathrm{gram}\right.$, $\mathrm{p}<0.05$ ), and the control group (vs. $8.56 \log _{10}$ CFU/gram, $\mathrm{p}<0.001$ ). Results were more impressive evaluating results against a vancomycin-resistant $E$. faecalis strain: ceftaroline vs. linezolid (3.98 vs. $6.88 \log _{10} \mathrm{CFU} / \mathrm{gram}, \mathrm{p}<0.001$ ), ceftaroline vs. vancomycin (vs. 8.01 $\log _{10} \mathrm{CFU} /$ gram, $\mathrm{p}<0.001$ ), and the control group (vs. $8.60 \log _{10} \mathrm{CFU} / \mathrm{gram}, \mathrm{p}<0.001$ ). In a rat endocarditis model, ceftaroline at $20 \mathrm{mg} / \mathrm{kg}$ IV twice daily was compared to control, vancomycin $120 \mathrm{mg} / \mathrm{kg}$ subcutaneously twice/daily, and daptomycin $10 \mathrm{mg} / \mathrm{kg}$ subcutaneously, daily administered for three days. Ceftaroline decreased bacterial densities significantly compared with controls in the vegetation (4.88 vs. $9.87 \log _{10} \mathrm{CFU} / \mathrm{gram}$, p <0.0005), kidney (4.09 vs. $7.28 \log _{10}$ CFU/gram, p<0.0005), and spleen (3.63 vs. 6.53 $\left.\log _{10} \mathrm{CFU} / \mathrm{gram}, \mathrm{p}<0.0005\right)$. Vancomycin and daptomycin decreased bacterial densities in the vegetation, liver, and spleen to 6.76 and $7.64 \log _{10} \mathrm{CFU} / \mathrm{gram}, 4.15$ and $5.53 \log _{10} \mathrm{CFU} /$ gram, and 4.28 and $5.49 \log _{10}$ CFU/gram, respectively. ${ }^{48}$

\section{Clinical Efficacy}

To date, phase III trials have been completed evaluating the efficacy of ceftaroline for the treatment of SSTI and CAP (Table 3). Regarding the treatment of SSTI, ceftaroline (600 mg intravenously every 12 hours) was noninferior to vancomycin (1 gram intravenously every 12 hours) plus aztreonam ( 1 gram intravenously every 8 hours) administered for 5-14 days. Two phase III trials, named CANVAS I and II (CEeftaroline versus Vancomycin in $\underline{S} k i n$ and Skin-Structure Infection), investigated complicated SSTI (most commonly extensive cellulitis, major abscess, and infected wounds) among 1,378 subjects comparing ceftaroline to vancomycin $+/-$ aztreonam. ${ }^{62}$ CANVAS I and II were randomized, double-blind, multinational phase III trials. Fifty-five study sites in 10 countries participated in CANVAS I from February to November $2007^{63}$ and 56 study sites in 12 countries participated in CANVAS II from March to December 2007. ${ }^{64}$ Eligibility requirements included age $\geq 18$ years and SSTI requiring $\geq 5$ days IV antibiotics. Four percent had concurrent bacteremia, and the most common cause of the SSTI was S. aureus. The clinical cure rates were $92 \%$ and $93 \%$ (non-significant difference), and microbiological eradication rates were $92 \%$ and 94\% for ceftaroline vs. the comparator. Response rates for MRSA infections were also similar. Ceftaroline was inferior to the comparator in Gram-negative SSTI, particularly for P. aeruginosa. Results from an earlier phase II trial ( $\mathrm{n}=100$, randomized 2:1) showed similar results - ceftaroline achieved clinical cure rates of $97 \%$ versus $89 \%$ for the comparator. In addition, the microbiological cure rates were comparable: $95 \%$ for ceftaroline (including all MRSA isolates identified) versus $86 \%$ for the comparator. ${ }^{65}$

Clinical trials have demonstrated efficacy utilizing ceftaroline for treating CAP (FOCUS 1 and 2: Ceftaroline Community Acquired Pneumonia Trial vs. Ceftriaxone in Hospitalized Patients). ${ }^{66,67}$ In these two phase III randomized double-blind multicenter trials, 1,228 hospitalized (but not admitted to the ICU) adults with moderate to severe (PORT risk class III or IV) CAP were randomized to ceftaroline (600 $\mathrm{mg}$ intravenously every 12 hours) or ceftriaxone ( 1 gram intravenously daily) for 5-7 days (Table 3 ). The overall clinical cure rates were similar (84\% in the ceftaroline group and $78 \%$ in the ceftriaxone group), as well as the overall microbiological response rate ( $87 \%$ for ceftaroline and $81 \%$ for ceftriaxone). The response rates were $86 \%$ and $69 \%$ against $S$. pneumoniae isolates and $100 \%(4 / 4)$ and $22 \%$ (2/9) against MDRSP for ceftaroline and ceftriaxone, respectively. Both drugs exhibited similar clinical cure rates against MSSA and Gram-negative respiratory pathogens, such as $H$. influenzae and K. pneumoniae. ${ }^{66,67}$ Therefore, individual and pooled analyses of the FOCUS trials demonstrate ceftaroline to be efficacious, well tolerated, and comparable in efficacy and adverse effects to ceftriaxone in the treatment of CAP. 
Although the number of cases were small, ceftaroline appears to be superior to ceftriaxone in the treatment of MDRSP as predicted by its superior affinity to the PBP2x (implicated in $\beta$-lactam resistance) ${ }^{67}$ As expected, ceftaroline is not targeted for hospital-acquired or aspiration pneumonia, as it lacks activity against many Gram-negative pathogens including those expressing AmpC- or ESBL, Pseudomonas, and Acinetobacter spp., as well as many anaerobes. Finally, given the paucity of MRSA cases in the FOCUS studies, data on the efficacy of ceftaroline for MRSA pneumonia are needed.

\section{Safety}

Based on clinical trial data to date, ceftaroline appears to be safe and well-tolerated. Since ceftaroline is a cephalosporin, it has caused serious hypersensitivity reactions in patients who are allergic to cephalosporins and among some patients with penicillin allergies. Hence, a careful history of prior antibiotic allergies should be obtained prior to the use of ceftaroline.

Side effects and drug discontinuation rates were similar to the comparator arm in the CANVAS studies. Among those receiving ceftaroline, the most common side effects were $6 \%$ with nausea, $5 \%$ headache, $5 \%$ diarrhea, $4 \%$ pruritis, and $3 \%$ rash. Forty-five percent had at least one adverse event (most were mild), but only $3 \%$ had to discontinue the drug, most commonly ascribed to a possible allergic reaction. ${ }^{62}$ All adverse events were similar to that of vancomycin/aztreonam, except the latter group had a higher incidence of pruritis. No cases of neutropenia, thrombocytopenia, hemolytic anemia, or significant liver dysfunction were identified during these trials. ${ }^{62}$ Elevations in laboratory parameters occurred infrequently for blood creatine kinase (8\%), alanine aminotransferase $(6 \%)$, and aspartate aminotransferase (6\%) levels, but were typically asymptomatic. ${ }^{63}$ Development of a positive direct Coombs' test has been noted, but no known cases of haemolytic anemia have been documented, thus far. Furthermore, EKG data have not noted QT interval prolongation. ${ }^{63}$ In summary, ceftaroline has had an excellent safety profile to date; further post-marketing assessments are needed to ensure the safety of this new drug.

Ceftaroline is excreted renally, thus studies have shown minimal impact on the fecal microflora after seven days administration in healthy young adults. For example, in one study, minimal disruption was noted in the stool ecologic flora, with modest decreases observed in E. coli, Bifidobacteria, and Lactobacillus isolates, and no changes were found within Candida, Bacterioides, or Enterococcus spp. ${ }^{43}$ However, like all antibiotics, $C$. difficile infection may occur with ceftaroline - in the CANVAS I and II trials, two patients (of 693) developed a C. difficile infection (compared to one in the comparator group) ${ }^{62}$

Regarding drug-drug interactions, no formal studies have been conducted with ceftaroline, to date. Given its metabolism through the kidneys, ceftaroline likely exhibits minimal inhibition of the P450 system, suggesting limited propensity for drug interactions among medications metabolized via this system. It has no known antagonism with other antibiotics and has possible synergy with diverse antibiotic classes, to include aminoglycosides (tobramycin), piperacillin/tazobactam, aztreonam, and meropenem. ${ }^{42,50} \mathrm{Up}$ to now, there are no specific data on the use of ceftaroline in paediatrics or pregnant/breastfeeding women, hence, the safety of this novel antibiotic in these settings is currently unknown.

\section{Resistance Barrier}

The barrier to resistance appears sizable for Gram-positive bacteria with resistance rarely reported to date. It has a comparable profile to other oxyimino cephalosporins for Gramnegative bacteria based on investigations of the spontaneous mutation frequency and change in MIC in single-step mutant selection and serial passage studies. ${ }^{23}$ For example, ceftaroline 
did not select for resistant variants of S. aureus in vivo. ${ }^{52}$ In vitro passage studies have demonstrated low rates of acquired resistance of Staphylococcus spp. to ceftaroline. ${ }^{51}$ Ceftaroline at concentrations of four times the MIC failed to select mutants atdetectable frequencies from tested MRSA, VISA, and MDRSP isolates. ${ }^{49}$ Ceftaroline also appeared immune to multi-step mutational induction attempts. ${ }^{49}$ In synopsis, ceftaroline has demonstrated minimal changes in MIC in serial passage studies in Gram-positive isolates, but demonstrates similar potential to resistance development as cefotaxime to Gramnegative organisms. ${ }^{23}$ Although these data are promising, information regarding the evolution of resistance to this novel antibiotic in clinical practice are needed. Furthermore, as previously noted, ceftaroline exhibits poor activity against ESBL and AmpC producing strains.

\section{Ceftobiprole}

There is an additional novel fifth-generation cephalosporin with activity against MRSA, ceftobiprole, currently under investigation. Ceftobiprole medocaril, the pro-drug of ceftobiprole (formerly BAL9141), is a parental investigational cephalosporin (pyrrolidinone-3-ylidene-methyl cephalosporin) for the treatment of SSTI with a recommended dose of $500 \mathrm{mg}$ every 8 hours for $7-14$ days. ${ }^{68,69}$ Ceftobiprole exhibits activity against a wide-range of Gram-positive organisms including (MRSA) and Gramnegative organisms mirroring cefepime and ceftazidime. ${ }^{70-71}$ Per time-kill studies, ceftobiprole exhibits primarily bactericidal activity with an $\mathrm{MBC} / \mathrm{MIC}<4$ for the majority of tested isolates. As with ceftaroline, ceftobiprole's activity against MRSA hinges upon its affinity and interaction with PBP2a. It acylates PBP2a rapidly forming a more stable acylenzyme complex than other cephalosporins leading to $100 \%$ inhibition $^{68}$. It also exhibits strong affinity for PBP2x providing activity against MDRSP, PBP2, PBP3 (E. coli), PBP1ab, PBP2, PBP3, PBP4 ( $P$. aeruginosa). Interestingly, ceftobiprole has no activity against Enterococcus faecium due to a lack of activity against PBP5. ${ }^{69}$ Ceftobiprole exhibits an $\mathrm{MIC}_{90}<2 \mu \mathrm{g} / \mathrm{mL}$ against MRSA and E. faecalis; and $0.25 \mu \mathrm{g} / \mathrm{mL}$ for sensitive $S$. pneumoniae and $<0.5 \mu \mathrm{g} / \mathrm{mL}$ against penicillin-resistant $S$. pneumoniae. ${ }^{68,70,71}$ Similar to ceftaroline, ceftobiprole exhibits vulnerability to many $\beta$-lactamases resulting in a wide range of MICs for the Enterobacteriaceae. ${ }^{71,72}$ Ceftobiprole is resistant to the TEM-1 and SHV-1 $\beta$-lactamases, but similar to ceftaroline, is susceptible to a host of higher order $\beta$ lactamases including AmpC $\beta$-lactamase; CTX-M-15 ESBL; and the KPC-2 carbapenemase.

Similar to ceftaroline, ceftobiprole has demonstrated noninferiority to vancomycin with or without ceftazidime in two large-scale studies with both interventions achieving clinical cure rates of $>90 \%{ }^{73,74}$. In the first phase III clinical trial, overall clinical cure rates for SSTI were $93 \%$ and $94 \%$ in the ceftobiprole and vancomycin groups, respectively (95\% CI, $-4.4 \%$ to $3.9 \%) .{ }^{73} \mathrm{~A}$ second phase III clinical trial noted overall cure rates of $91 \%$ versus $90 \%$ compared to vancomycin plus ceftazidime without significant differences in adverse events. ${ }^{74}$ Ceftobiprole is approved for the treatment of SSTI in Switzerland and Canada (Zevtera). However, the drug has not been approved by the FDA and is pending further evaluation. ${ }^{75}$

\section{Conclusions}

Ceftaroline is a novel, broad-spectrum cephalosporin, which exhibits bactericidal activity against Gram-positive bacteria, including MRSA and MDRSP. Ceftaroline offers an exciting addition to the anti-MRSA armamentarium, including activity against VISA, hVISA, VRSA, and daptomycin- and linezolid-resistant strains. Unique among many antiMRSA agents, ceftaroline additionally provides activity against Gram-negative respiratory pathogens including $H$. influenzae and $M$. catarrhalis. Since ceftaroline is not effective 
against organisms with AmpC- or ESBLs, research investigating combination with $\beta$ lactamase inhibitors to provide potential activity against these Gram-negative organisms are underway. To date, ceftaroline has demonstrated an excellent safety profile comparable to contemporary cephalosporins and exhibits an inherently low propensity to inducing resistance, especially among Gram-positive organisms; however, long-term data and clinical experience with this novel agent are needed. Ceftaroline is currently FDA approved for the treatment of both STTIs and CAP.

\section{References}

1. Moran G, Krishnadasan A, Gorwitz R, et al. Methicillin-resistant S. aureus Infections Among Patients in the Emergency Department. N Engl J Med. 2006; 355(7):666-674. [PubMed: 16914702]

2. Gonzalez BE, Hulten KG, Dishop MK, et al. Pulmonary Manifestations in Children with Invasive Community-acquired Staphylococcus aureus Infection. Clin Infect Dis. 2005; 41(5):583-590. [PubMed: 16080077]

3. Sievert DM, Rudrik JT, Patel JB, McDonald LC, Wilkins MJ, Hageman JC. Vancomycin-resistant Staphylococcus aureus in the United States, 2002-2006. Clin Infect Dis. 2008; 46(5):668-674. [PubMed: 18257700]

4. Stryjewski ME, Corey GR. New Treatments for Methicillin-resistant Staphylococcus aureus. Curr Opin Crit Care. 2009; 15(5):403-412. [PubMed: 19561492]

5. Pan A, Lorenzotti S, Zoncada A. Registered and Investigational Drugs for the Treatment of Methicillin-resistant Staphylococcus aureus Infection. Recent Pat Antiinfect Drug Discov. 2008; 3(1):10-33. [PubMed: 18221183]

6. Manfredi R, Sabbatani S. Novel Pharmaceutical Molecules Against Emerging Resistant Grampositive Cocci. Braz J Infect Dis. 2010; 14(1):96-108. [PubMed: 20428664]

7. Stryjewski ME, Graham DR, Wilson SE, et al. Assessment of Telavancin in Complicated Skin and Skin-Structure Infections Study. Telavancin Versus Vancomycin for the Treatment of Complicated Skin and Skin-structure Infections Caused by Gram-positive Organisms. Clin Infect Dis. 2008; 46(11):1683-1693. [PubMed: 18444791]

8. Stefani S, Goglio A. Methicillin-resistant Staphylococcus aureus: Related Infections and Antibiotic Resistance. Int J Infect Dis. 2010; 14S4:S19-S22. [PubMed: 20843722]

9. Livermore D. Linezolid in vitro: mechanism and antibacterial spectrum. J Antimicrob Chemother. 2003; 51(S2):S9-S16.

10. Manfredi R. Update on the Appropriate Use of Linezolid in Clinical Practice. Ther Clin Risk Manage. 2006; 2(4):455-463.

11. Nannini E, Murray BE, Arias CA. Resistance or Decreased Susceptibility to Glycopeptides, Daptomycin, and Linezolid in Methicillin-resistant Staphylococcus aureus. Curr Opin Pharmacol. 2010; 10(5):516-521. [PubMed: 20598637]

12. Koplowicz YB, Schwartz BS, Guglielmo BJ. Development of Daptomycin-susceptible, Methicillin-resistant Staphylococcus aureus Pneumonia During High-dose Daptomycin Therapy. Clin Infect Dis. 2009; 49(8):1286-1287. [PubMed: 19780665]

13. Marty F, Yeh W, Wennersten C, et al. Emergence of a Clinical Daptomycin-Resistant Staphylococcus aureus Isolate during Treatment of Methicillin-Resistant Staphylococcus aureus Bacteremia and Osteomyelitis. J Clin Microbiol. 2006; 44(2):595-597. [PubMed: 16455920]

14. Hayden MK, Rezai K, Hayes RA, Lolans K, Quinn JP, Weinstein RA. Development of Daptomycin Resistance In Vivo in Methicillin-Resistant Staphylococcus aureus. J Clin Microbiol. 2005; 43(10):5285-5287. [PubMed: 16207998]

15. Sakoulas G, Alder J, Thauvin-Eliopoulos C, Moellering R, Eliopoulos G. Induction of Daptomycin Heterogenous Susceptibility in Staphylococcus aureus by Exposure to Vancomycin. Antimicrob Agents Chemother. 2006; 50(4):1581-1585. [PubMed: 16569891]

16. Rose W, Leonard S, Sakoulas G, et al. Daptomycin Activity against Staphylococcus aureus following Vancomycin Exposure in an In Vitro Pharmacodynamic Model with Simulated Endocardial Vegetation. Antimicrob Agents Chemother. 2008; 52(3):831-836. [PubMed: 17999971] 
17. Peterson LR. A review of tigecycline-the first glycylcycline. Int J Antimicrob Agents. 2008; 32(S4):S215-222. [PubMed: 19134522]

18. Reygaert W. Antibiotic Optimization in the Difficult-to-treat Patient with Complicated Intraabdominal or Complicated Skin and Skin Structure Infections: Focus on Tigecycline. Ther Clin Risk Manag. 2010; 6:419-430. [PubMed: 20856688]

19. Freire A, Melnyk V, Kim M, et al. Comparison of Tigecycline with Imipenem/Cilastatin for the Treatment of Hospital-acquired Pneumonia. Diagn Microbiol Infect Dis. 2010; 68(2):140-151. [PubMed: 20846586]

20. Ge Y, Biek D, Talbot G, Sahm D. In Vitro Profiling of Ceftaroline Against a Collection of Recent Bacterial Clinical Isolates from Across the United States. Antimicrob Agents Chemother. 2008; 52(9):3398-3407. [PubMed: 18625769]

21. Sader H, Fritsche T, Kaniga K, Ge Y, Jones R. Antimicrobial Activity and Spectrum of PPI-0903M (T-91825), a Novel Cephalosporin, Tested Against a Worldwide Collection of Clinical Strains. Antimicrob Agents Chemother. 2005; 49(8):3501-3512. [PubMed: 16048970]

22. Steed M, Rybak MJ. Ceftaroline. A New Cephalosporin with Activity Against esistant Grampositive Pathogens. Pharmacotherapy. 2010; 30(4):375-389. [PubMed: 20334458]

23. Zhanel G, Sniezek G, Schweizer F, et al. Ceftaroline: A Novel Broad-spectrum Cephalosporin with Activity Against Methicillin-resistant Staphylococcus aureus. Drugs. 2010; 69(7):809-831. [PubMed: 19441869]

24. Vidaillac C, Leonard S, Rybak M. In Vitro Activity of Ceftaroline Against Methicillin-resistant Staphylococcus aureus and Heterogeneous Vancomycin-intermediate S. aureus in a Hollow Fiber Model. Antimicrob Agents Chemother. 2009; 53(11):4712-4717. [PubMed: 19738009]

25. Villegas-Estrada A, Lee M, Hesek D, Vakulenko S, Mobashery S. Co-opting the Cell Wall in Fighting Methicillin-resistant Staphylococcus aureus: Potent Inhibition of PBP 2a by Two AntiMRSA $\beta$-lactam Antibiotics. J Am Chem Soc. 2008; 130(29):9212-9213. [PubMed: 18582062]

26. Kanafani Z, Corey R. Ceftaroline: A Cephalosporin with Expanded Gram- positive Activity. Future Microbiol. 2009; 4(1):25-33. [PubMed: 19207097]

27. Llarrull L, Fisher J, Mobashery S. Molecular Basis and Phenotype of Methicillin Resistance in Staphylococcus aureus and Insights into New beta-lactams that Meet the Challenge. Antimicrob Agents Chemother. 2009; 53(10):4051-4063. [PubMed: 19470504]

28. Moisan H, Pruneau M, Malouin F. Binding of Ceftaroline to Penicillin-binding Proteins of Staphylococcus aureus and Streptococcus pneumoniae. J Antimicrob Chemother. 2010; 65(4): 713-716. [PubMed: 20097788]

29. Kosowska-Shick K, McGhee PL, Appelbaum PC. Affinity of Ceftaroline and Other Beta-lactams for Penicillin-binding Proteins from Staphylococcus aureus and Streptococcus pneumoniae. Antimicrob Agents Chemother. 2010; 54(5):1670-1677. [PubMed: 20194704]

30. Sader H, Fritsche T, Jones R. Antimicrobial Activities of Ceftaroline and ME1036 Tested Against Clinical Strains of Community-acquired Methicillin-resistant Staphylococcus aureus. Antimicrob Agents Chemother. 2008; 52(3):1153-1155. [PubMed: 18180353]

31. Ge, Y.; Floren, L.; Redman, R.; Wikler, M.; Liao, S. Single-dose Pharmacokinetics (PK) of Ceftaroline (PPI-0903) in Healthy Subjects [abstract A-1936]. 46th Interscience Conference on Antimicrobial Agents and Chemotherapy; Sept 27-30, 2006; San Francisco CA.

32. Ge, Y.; Redman, R.; Floren, L.; Liao, S.; Wilker, M. The Pharmacokinetics (PK) and Safety of Ceftaroline (PPI-0903) in Healthy Subjects Receiving Multiple-dose Intravenous (IV) Infusions [abstract A-1937]. 46th Interscience Conference on Antimicrobial Agents and Chemotherapy; Sept 27-30, 2006; San Francisco CA.

33. Ge Y, Maynard D, Rickert DE. Comparative Pharmacokinetics of Ceftaroline in Rats, Rabbits, and Monkeys Following a Single Intravenous or Intramuscular Injection. Antimicrob Agents Chemother. 2010; 54(2):912-914. [PubMed: 19949051]

34. Riccobene, T.; Fang, E.; Thye, D. A Single- and Multiple-dose Study to Determine the Safety, Tolerability, and Pharmacokinetics (PK) of Ceftaroline (CPT) Administered by Intramuscular (IM) Injection to Healthy Subjects [abstract A-1888]. 48th International Conference on Antimicrobial Agents and Chemotherapy/Infectious Disease Society of America 46th Annual Meeting; October 25-28, 2008; Washington DC. 
35. Ge, Y.; Thye, D.; Liao, S., et al. Pharmacokinetics (PK) of Ceftaroline (PPI0903) in Subjects with Mild or Moderate Renal Impairment (RI) [abstract A-1939]. 46th Interscience Conference on Antimicrobial Agents and Chemotherapy; Sept 27-30, 2006; San Francisco CA.

36. Ge, Y.; Liao, S.; Talbot, GH. Population Pharmacokinetics (PK) Analysis of Ceftaroline (CPT) in Volunteers and Patients with Complicated Skin and Skin Structure Infections (CSSSI) [abstract A-34]. 46th Interscience Conference on Antimicrobial Agents and Chemotherapy; Sept 27-30, 2006; San Francisco CA.

37. Jacqueline, C.; Caillon, J.; Miegeville. Penetration of Ceftaroline (PPI-0903), a New Cephalosporin, into Lung Tissues: Measurement of Plasma and Lung Tissue Concentrations after a Short IV Infusion in the Rabbit [abstract A-1938]. 46th Interscience Conference on Antimicrobial Agents and Chemotherapy; Sept 27-30, 2006; San Francisco CA.

38. McGee L, Biek D, Ge Y, et al. In vitro Evaluation of the Antimicrobial Activity of Ceftaroline Against Cephalosporin-resistant Isolates of Streptococcus pneumoniae. Antimicrob Agents Chemother. 2009; 53(2):552-556. [PubMed: 19015339]

39. Ge, Y.; Liao, S.; Thye, DA., et al. Ceftaroline (CPT) Dose Adjustment Recommendations for Subjects with Mild or Moderate Renal Impairment (RI). [abstract A-35]. 46th Interscience Conference on Antimicrobial Agents and Chemotherapy; Sept 27-30, 2006; San Francisco CA.

40. Bazan JA, Martin SI, Kaye KM. Newer Beta-lactam Antibiotics: Doripenem, Ceftobiprole, Cetaroline and Cefepime. Infect Dis Clin N Am. 2009; 23:983-996.

41. Riccobene, T.; Jakate, A.; Rank, D.; Thye, DA. An Open-label, Pharmacokinetic, Safety and Tolerability Study of Single-dose Intravenous Ceftaroline in Subjects with End-stage Renal Disease on Intermittent Haemodialysis. Poster Presentation at the European Congress of Clinical Microbiology and Infectious Diseases; Helsinki, Finland. May 16-19, 2009;

42. Parish D, Scheinfeld N. Ceftaroline Fosamil, A Cephalosporin Derivative for the Potential Treatment of MRSA Infection. Curr Opin Invest Drugs. 2008; 9(2):201-209.

43. Panagiotidis G, Backstrom T, Asker-Hagelberg C, Jandourek A, Weintraub A, Nord CE. Effect of Ceftaroline on Normal Human Intestinal Microflora. Antimicrob Agents Chemother. 2010; 54(5): 1811-1814. [PubMed: 20231399]

44. Andes D, Craig WA. Pharmacodynamics of a New Cephalosporin, PPI-0903 (TAK-599), Active Against Methicillin-resistant Staphylococcus aureus in Murine Thigh and Lung Infection Models: Identification of an In Vivo Pharmacokinetic-pharmacodynamic Target. Antimicrob Agents Chemother. 2006; 50(4):1376-1383. [PubMed: 16569855]

45. Brown S, Traczewski M. In vitro Antimicrobial Activity of a New Cephalosporin, Ceftaroline, and Determination of Quality Control Ranges for MIC Testing. Antimicrob Agents Chemother. 2009; 53(3):1271-1274. [PubMed: 19114671]

46. Jones R, Fritsche T, Ge Y, Kaniga K, Sader H. Evaluation of PPI-0903M (T91825), A Novel Cephalosporin: Bactericidal Activity, Effects of Modifying In Vitro Testing Parameters and Optimization of Disc Diffusion Tests. J Antimicrob Chemother. 2005; 56(6):1047-1052. [PubMed: 16239290]

47. Pankuch G, Appelbaum P. Postantibiotic Effect of Ceftaroline Against Gram- positive Organisms. Antimicrob Agents Chemother. 2009; 53(10):4537-4539. [PubMed: 19770288]

48. Jacqueline C, Caillon J, Le Mabecque V, et al. In vivo Activity of a Novel Anti-methicillinresistant Staphylococcus aureus Cephalosporin, Ceftaroline, Against Vancomycin-susceptible and -resistant Enterococcus faecalis Strains in a Rabbit Endocarditis model: A Comparative Study with Linezolid and Vancomycin. Antimicrob Agents Chemother. 2009; 53(12):5300-5302. [PubMed: 19752276]

49. Mushtaq S, Warner M, Ge Y, Kaniga K, Livermore D. In Vitro Activity of Ceftaroline (PPI-0903M, T-91825) Against Bacteria with Defined Resistance Mechanisms and Phenotypes. J Antimicrob Chemother. 2007; 60(2):300-311. [PubMed: 17548456]

50. Vidaillac C, Leonard S, Rybak M. In Vitro Evaluation of Ceftaroline Alone and in Combination with Tobramycin Against Hospital-acquired Methicillin-Resistant Staphylococcus aureus (HAMRSA) Isolates. Int J Antimicrob Agents. 2010; 35(6):527-530. [PubMed: 20346632]

51. Saravolatz L, Pawlak J, Johnson L. In Vitro Activity of Ceftaroline Against Community Associated Methicillin Resistant, Vancomycin Intermediate, Vancomycin Resistant, and Daptomycin Non 
Susceptible Staphylococcus aureus Isolates. Antimicrob Agents Chemother. 2010; 54(7):30273030. [PubMed: 20404122]

52. Jacqueline C, Caillon J, Le Mabecque V, et al. In Vivo Efficacy of Ceftaroline (PPI-0903), a New Broad-spectrum Cephalosporin, Compared with Linezolid and Vancomycin Against Methicillinresistant and Vancomycin-intermediate Staphylococcus aureus in a Rabbit Endocarditis Model. Antimicrob Agents Chemother. 2007; 51(9):3397-3400. [PubMed: 17591849]

53. Jacobs M, Good C, Windau A, et al. Activity of Ceftaroline Against Recent Emerging Serotypes of Streptococcus pneumoniae in the United States. Antimicrob Agents Chemother. 2010; 54(6): 2716-2719. [PubMed: 20308374]

54. Patel S, Pillai D, Pong-Porter S, McGeer A, Green K, Low DE. In Vitro Activity of Ceftaroline, Ceftobiprole and Cethromycin Against Clinical Isolates of Streptococcus pneumoniae Collected from Across Canada Between 2003 and 2008. J Antimicrob Chemother. 2009; 64(3):659-660. [PubMed: 19578080]

55. Fenoll A. In Vitro Activity of Ceftaroline Against Streptococcus pneumoniae Isolates Exhibiting Resistance to Penicillin, Amoxicillin, and Cefotaxime. Antimicrob Agents Chemother. 2008; 52(11):4209-4210. [PubMed: 18725443]

56. Morrissey I, Ge Y, Janes R. Activity of the New Cephalosporin Ceftaroline Against Bacteraemia Isolates from Patients with Community-acquired Pneumonia. Int J Antimicrob Agents. 2009; 33(6):515-519. [PubMed: 19203863]

57. Mushtaq S, Warner M, Williams G, Crithcley I, Livermore D. Activity of Checquerboard Combinations of Ceftaroline and NXL104 Versus Beta-lactamase Producing Enterobacteriaceae. J Antimicrob Chemother. 2010; 65(7):1428-1432. [PubMed: 20478991]

58. Mushtaq S, Warner M, Livermore D. In Vitro Activity of Ceftazidime+NXL104 Against Pseudomonas aeruginosa and Other Non-fermenters. J Antimicrob Chemother. 2010; 65(11): 2376-2381. [PubMed: 20801783]

59. Citron D, Tyrrell K, Merriam C, Goldstein E. In Vitro Activity of Ceftaroline Against 623 Diverse Strains of Anaerobic Bacteria. Antimicrob Agents Chemother. 2010; 54(4):1627-1632. [PubMed: 20100877]

60. Iizawa Y, Nagai J, Ishikawa T, et al. In vitro Antimicrobial Activity of T-91825, a Novel AntiMRSA Cephalosporin, and In Vivo Anti-MRSA Activity of its Prodrug, TAK-599. J Infect Chemother. 2004; 10(3):146-156. [PubMed: 15290453]

61. Jacqueline C, Amador G, Caillon J, et al. Efficacy of the New Cephalosporin Ceftaroline in the Treatment of Experimental Methicillin-resistant Staphylococcus aureus Acute Osteomyelitis. J Antimicrob Chemother. 2010; 65(8):1749-1752. [PubMed: 20530506]

62. Corey GR, Wilcox M, Talbot GH, Friedland HD, Baculik T, Witherell GW, Critchley I, Das AF, Thye D. Integrated Analysis of CANVAS 1 and 2: Phase 3, Multicenter, Randomized, Doubleblind Studies to Evaluate the Safety and Efficacy of Ceftaroline Versus Vancomycin Plus Aztreonam in Complicated Skin and Skin-structure Infection. Clin Infect Dis. 2010; 51(6):641650. [PubMed: 20695801]

63. Corey GR, Wilcox MH, Talbot GH, Thye D, Friedland D, Baculik T. CANVAS 1 investigators. CANVAS 1: The First Phase III, Randomized, Double-blind Study Evaluating Ceftaroline fosamil for the Treatment of Patients with Complicated Skin and Skin Structure Infections. J Antimicrob Chemother. 2010; 65(S4):S41-51.

64. Wilcox MH, Corey GR, Talbot GH, Thye D, Friedland D, Baculik T. CANVAS 2 investigators. CANVAS II: The Second Phase III, Randomized, Double-blind Study Evaluating Ceftaroline fosamil for the Treatment of Patients with Complicated Skin and Skin Structure Infections. J Antimicrob Chemother. 2010; 65(S4):S53-S65.

65. Talbot G, Thye D, Das A, Ge Y. Phase 2 Study of Ceftaroline Versus Standard Therapy in Treatment of Complicated Skin and Skin Structure Infections. Antimicrob Agents Chemother. 2007; 51(10):3612-3616. [PubMed: 17682094]

66. Eckburg, P.; Friedland, HD.; Lee, J.; Llorens, L.; Critchley, IA.; Thye, DA. FOCUS 1 and 2: Randomized, Double-blinded, Multicenter Phase 3 Trials of the Efficacy and Safety of Ceftaroline (CPT) VS Ceftriaxone (CRO) in Community-acquired Pneumonia (CAP) [Abstract LI-345a]. Poster presentation at the 49th Interscience Conference on Antimicrobial Agents and Chemotherapy; San Francisco, CA. September 12-15, 2009; 
67. File TM Jr, Low DE, Eckburg PB, Talbot GH, Friedland HD, Lee J, Llorens L, Critchley I, Thye D. Integrated analysis of FOCUS 1 and FOCUS 2: Randomized Double-Blinded, Multicenter Phase 3 Trials of the Efficacy and Safety of Ceftaroline fosamil versus Ceftriaxone in Patients with Community-acquired Pneumonia. Clin Infect Dis. 2010; 51(2):1395-1405. [PubMed: 21067350]

68. Dauner D, Nelson R, Taketa D. Ceftobiprole: A novel, Broad-spectrum Cephalosporin with Activity Against Methicillin-resistant Staphylococcus aureus. Am J Health Syst Pharm. 2010; 67(12):983-993. [PubMed: 20516468]

69. Barbour A, Derendorf H. Resistance and the Management of Complicated Skin and Skin Structure Infections: the Role of Ceftobiprole. Ther Clin Risk Manag. 2010; 6:485-495. [PubMed: 20957140]

70. Betriu C, Culebras E, Gomez M, Lopez-Fabal F, Rodriguez-Avial I, Picazo JJ. Comparative in vitro Activity of Ceftobiprole against Gram-positive Cocci. Int J Antimicrob Agents. 2010; 36(2): 111-113. [PubMed: 20554163]

71. Fritsche TR, Sader HS, Jones RN. Antimicrobial activity of Ceftobiprole, a Novel Anti-methicillinresistant Staphylococcus aureus Cephalosporin, Tested against Contemporary Pathogens: Results from the SENTRY Antimicrobial Surveillance Program (2005-2006). Diagn Microbiol Infect Dis. 2008; 61(1):86-95. [PubMed: 18385000]

72. Silva N, Radhouani H, Goncalves A, Araujo C, Rodrigues J, Igrejas G, Poeta P. In vitro Activity of Ceftobiprole against Gram-positive and Gram-negative Bacteria Isolated from Humans and Animals. J Antimicrob Chemother. 2010; 65(4):801-803. [PubMed: 20110342]

73. Noel GJ, Strauss RS, Amsler K, Heep M, Pypstra R, Solomkin JS. Results of a Double-blind, Randomized Trial of Ceftobiprole Treatment of Complicated Skin and Skin Structure Infections caused by Gram-positive Bacteria. Antimicrob Agents Chemother. 2008; 52(1):37-44. [PubMed: 17954698]

74. Noel GJ, Bush K, Bagchi P, Ianus J, Strauss RS. A Randomized, Double-blind Trial Comparing Ceftobiprole medocaril with Vancomycin plus Ceftazidime for the Treatment of Patients with Complicated Skin and Skin-structure Infections. Clin Infect Dis. 2008; 46(5):647-655. [PubMed: 18225981]

75. Chahine E. Ceftobiprole: Farewell or Just a Delay? Am J Health Syst Pharm. 2010; 67(12):981. [PubMed: 20516467] 
<smiles>CCO/N=C(\C(=O)N[C@@H]1C(=O)N2C(C(=O)[O-])=C(SC3=NC(c4cc[n+](C)cc4)CS3)CS[C@H]12)c1nsc(NP(=O)(O)O)n1</smiles>

Figure 1.

Chemical Structure of Ceftaroline fosamil acetate 
S. aureus with PBP

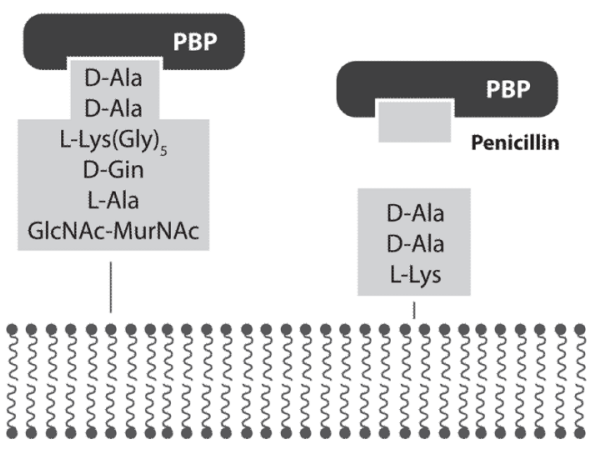

MRSA with Mutated PBP (PBP2a)

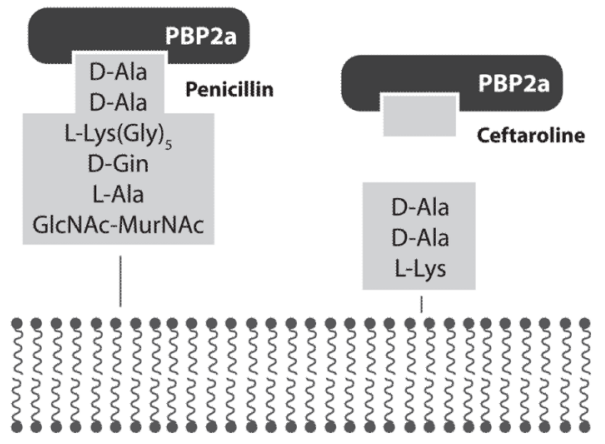

Figure 2. 
Table 1

Ceftraroline's Mean Inhibitory Concentrations (MICs) for Selected Organisms

\begin{tabular}{|c|c|}
\hline Organism & $\mathrm{MIC}_{90}(\mu \mathrm{g} / \mathrm{ml})$ \\
\hline \multicolumn{2}{|l|}{ Gram-Positive Bacteria } \\
\hline \multicolumn{2}{|l|}{ Staphylococcus aureus } \\
\hline MSSA & $0.25 \mu \mathrm{g} / \mathrm{ml}(\leq 0.03-1.0)$ \\
\hline MRSA & $0.5-2.0$ \\
\hline hVISA & $0.25-4.0$ \\
\hline Quinupristin-dalfopristin-resistant & 1 \\
\hline \multicolumn{2}{|l|}{ Staphylococcus epidermidis } \\
\hline Oxacillin-sensitive & $0.12(0.06-0.12)$ \\
\hline Oxacillin-resistant & $0.5(0.25-2.0)$ \\
\hline Vancomycin-intermediate (VISE) & $\leq 0.016-2.0$ \\
\hline Quinupristin-dalfopristin-resistant & 1.0 \\
\hline Linezolid-resistant & 0.5 \\
\hline \multicolumn{2}{|l|}{ Streptococcus pneumoniae } \\
\hline Penicillin-susceptible & 0.015 \\
\hline Penicillin-intermediate & 0.06 \\
\hline Penicillin-resistant (MDRSP) & $(0.12-0.25)$ \\
\hline Ceftazidime-resistant & 1.0 \\
\hline Ceftriaxone- and cefotaxime-resistant & 0.25 \\
\hline Erythromycin-resistant & 0.25 \\
\hline Levofloxacin-resistant & 0.12 \\
\hline Streptococcus ( $\beta$ hemolytic) & $<0.008-0.016$ \\
\hline Enterococcus faecalis & $2.0-4.0$ \\
\hline Enterococcus faecium & $16-64$ \\
\hline \multicolumn{2}{|l|}{ Gram-Negative Bacteria } \\
\hline H. influenzae & $<0.016-0.03$ \\
\hline Enterobacteriaceae & \\
\hline
\end{tabular}




\begin{tabular}{|c|c|}
\hline Organism & $\operatorname{MIC}_{90}(\mu \mathrm{g} / \mathrm{ml})$ \\
\hline No $\beta$-lactamases & $0.06-4.0$ \\
\hline ESBL positive & $>32$ \\
\hline AmpC positive & $>128$ \\
\hline Citrobacter freundii & 2.0 \\
\hline \multicolumn{2}{|l|}{ E. coli } \\
\hline All isolates & 0.12 \\
\hline - TEM/SHV & $0.015-0.03$ \\
\hline+ TEM/SHV & $0.5-2.0$ \\
\hline Klebsiella pneumoniae & 0.5 \\
\hline Morganella morganii & 0.12 \\
\hline Proteus mirabilis & 0.12 \\
\hline Serratia marcescens & 2.0 \\
\hline \multicolumn{2}{|l|}{ Non-Enterobacteriaceae } \\
\hline Pseudomonas spp. & $>32$ \\
\hline Acinetobacter spp. & $4->128$ \\
\hline Stenotrophomonas maltophila & $>32$ \\
\hline \multicolumn{2}{|l|}{ Anaerobes } \\
\hline Peptostreptococcus spp. & 0.12 \\
\hline Propionibacterium spp & 0.12 \\
\hline Bacteroides spp. & $>32$ \\
\hline Prevotella spp. & $>32$ \\
\hline Pasteurella multocida & 0.06 \\
\hline Clostridium difficile & 4 \\
\hline
\end{tabular}




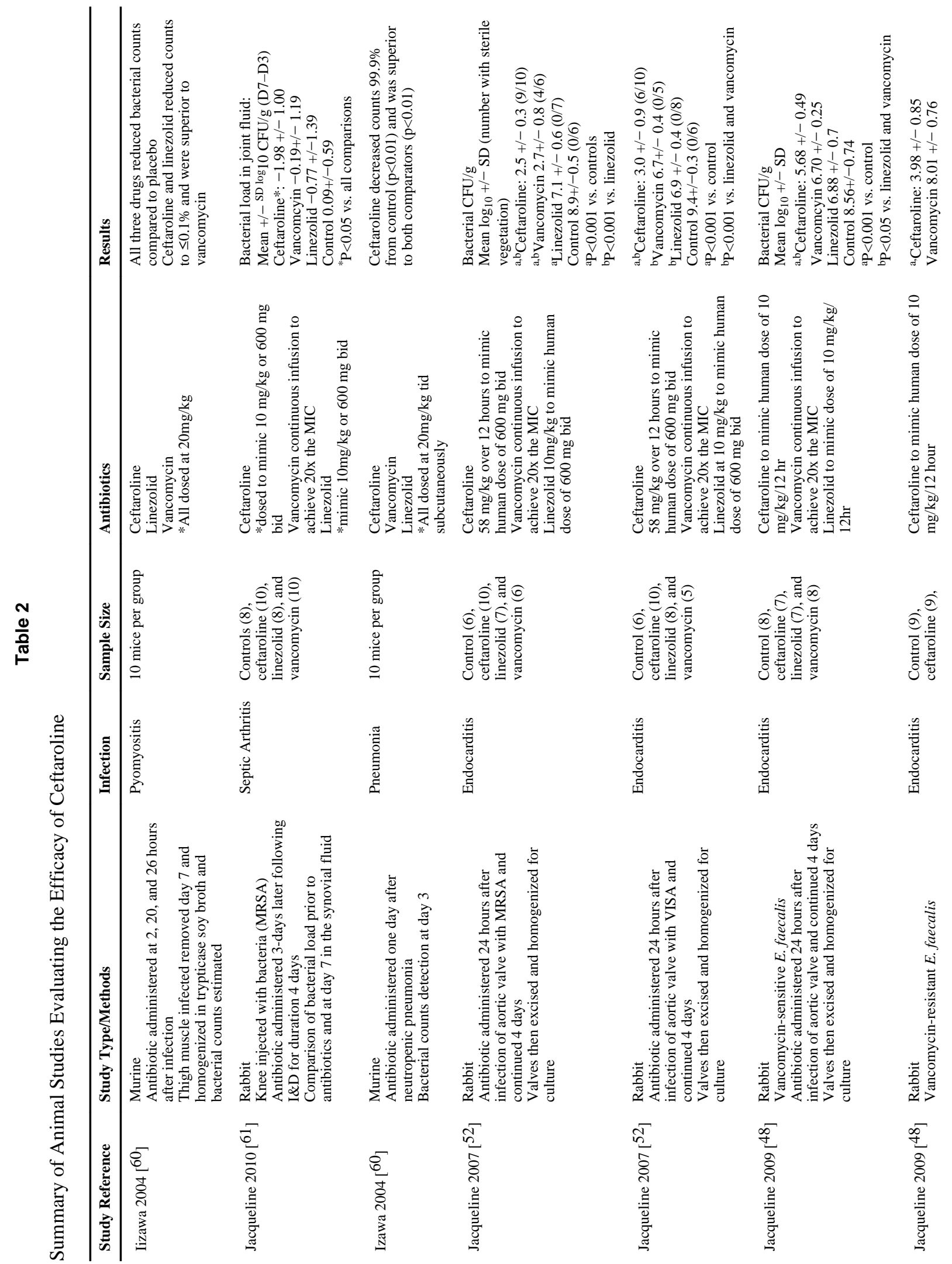




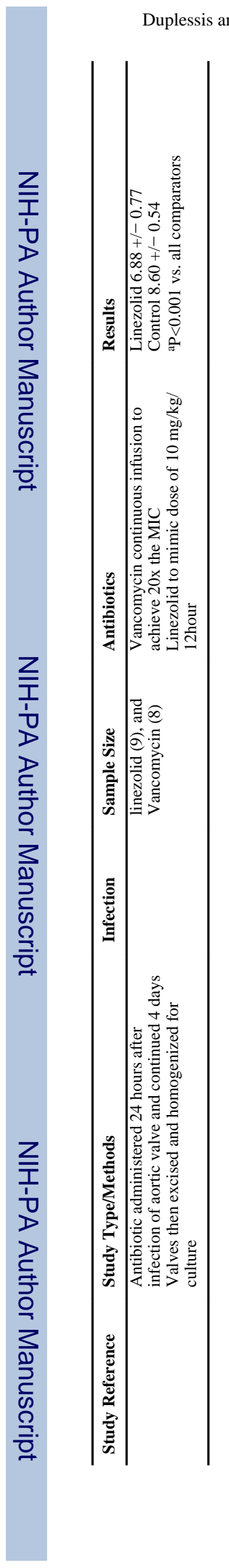

Page 23 


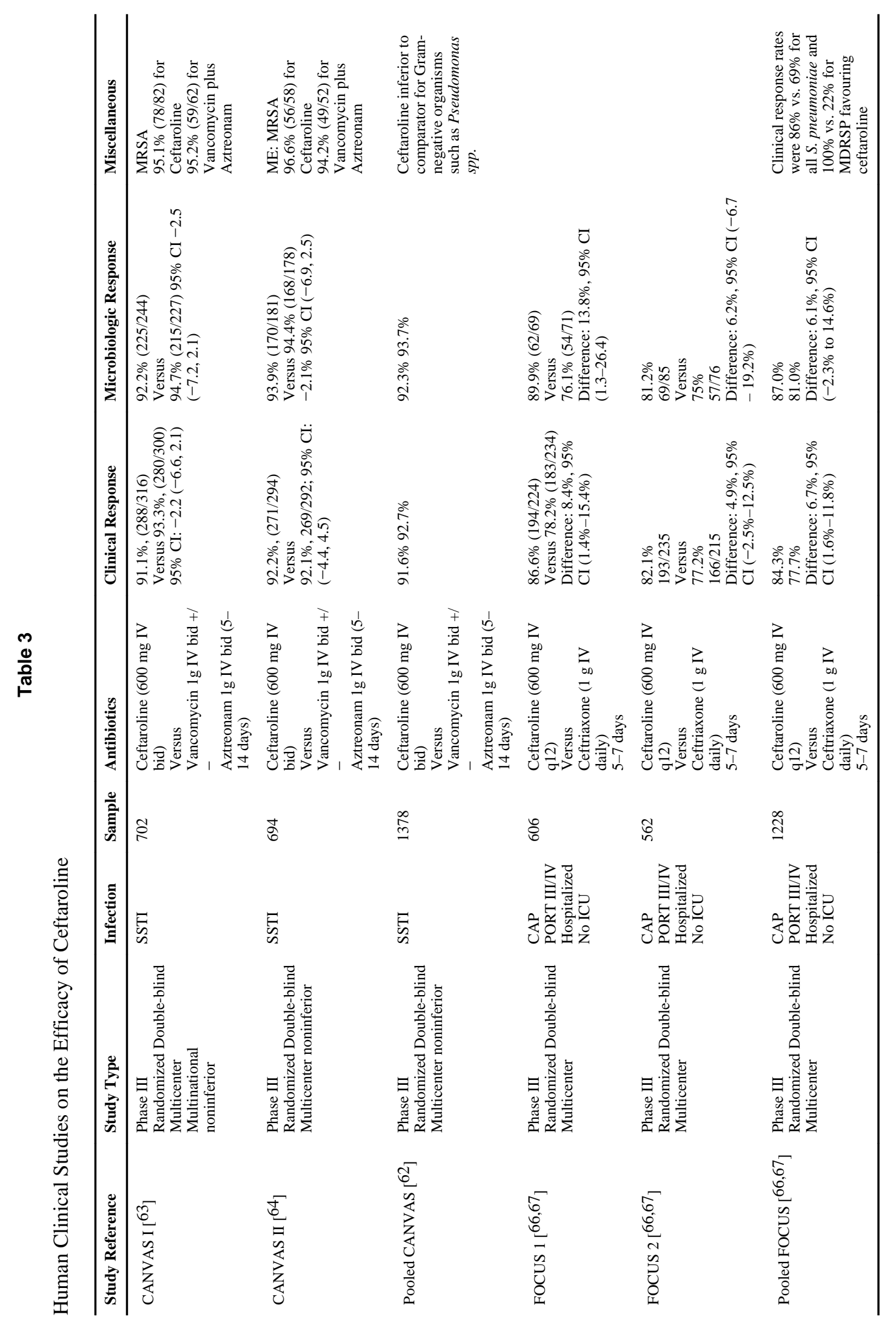

